\title{
ECONOMÍA, ÉTICA Y CORRUPCIÓN
}

\section{ECONOMICS, ETHICS AND CORRUPTION}

\author{
DORA ESTHER AYALA ROJAS
}

FACULTAD DE DERECHO Y CIENCIAS SOCIALES Y POLÍTICAS UNIVERSIDAD NACIONAL DEL NORDESTE

ARGENTINA

El portador de un ideal va por caminos rectos, sin reparar que sean ásperos y abruptos. No transige nunca movido por vil interés; repudia el mal cuando concibe el bien; ignora la duplicidad; ama en la Patria a todos sus conciudadanos y siente vibrar en la propia el alma de toda la Humanidad. 


\begin{tabular}{c}
\hline $198<$ DORA ESTHER AYALA ROJAS \\
ECONOMÍA, ÉTICA Y CORRUPCIÓN \\
Págs. 197-212
\end{tabular}

Recibido: 17/06/2016

Aceptado: 01/09/2016

\section{RESUMEN}

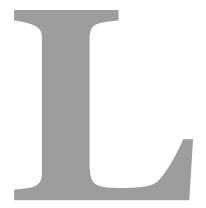

a relación de la Economía con la Ética se presenta desde el inicio de nuestra tradición disciplinar como foco de conflictos que contribuye a cierto aislamiento respecto de las ciencias sociales hermanas. Este condicionamiento deriva de una tesis fuerte y ampliamente difundida durante el siglo XX que afirma: la actividad económica es un quehacer para optimizar beneficios al máximo y está libre de influencias morales. Abre paso a considerarla como proclive a las prácticas corruptas y compromete a quienes desde la academia abordamos la disciplina, a un gran esfuerzo por rebatirla y superarla; tarea que queda explícitamente planteada como objetivo principal de nuestra colaboración. Partiendo del dato histórico que la Economía surge científicamente en el ámbito de la Ética a partir de la difusión de la obra maestra de Adam Smith (1776) indagamos, con una metodología crítica e integrada en complejidad disciplinar, en las razones por las que se generalizó su uso a aceptar todo tipo de actividades que justificaran un interés para los involucrados, suponiendo siempre: la legitimidad de los acuerdos basados en la autonomía de la voluntad; el enfoque de responsabilidades en el sector público con exclusión de las prácticas corruptas del sector privado; y el menosprecio de su impacto en el desarrollo. El trabajo concluye sosteniendo que la actividad económica es un quehacer ético por su origen (cuidado del bien común) su episteme (toma de decisiones moralmente valiosas) y su ejecución (políticas de desarrollo enfatizadas en la vulnerabilidad).

Palabras Clave: preferencias; beneficios; valores.

\section{ABSTRACT}

The relationship between Economics and Ethics is presented since the beginning of our disciplinary tradition as the conflict center that contributes to an isolation from the related social science. This condition derives from a strongly and widely spread thesis from the 20th century, which asserts that the economical activity is a task to maximize benefits and it is free from moral influence. The thesis leads the way to be considered as prone to corrupted activities and compromise those people who deal, in this world, with the discipline. It makes a serious effort to repel and overcome the corrupted activity. The task explicitly proposed is stated as the aim of this work; starting with the dissemination of Adam Smith's masterpiece (1776), economics appears scientifically from the ethics sphere. It is inquired, with a critical and integrated methodology in a complex discipline, the reasons why its use becomes general in every type of activity justifies a particular interest to those who are involved. This methodology is always used whenever the legitimate arrangements are based on the autonomy of the will; the responsibilities approach in 
public sector is concerned with the exclusion of the corrupted practices from private sector; and the impact on its development. To conclude, the work maintains that the economical activity is an ethical task because of its origin (care for the common good) its episteme (to make morally valuable decisions) and because its realization (developmental policies emphasized in the vulnerability).

Keyword: preferences; benefits; values.

\section{INTRODUCCIÓN}

La relación de la Economía con la Ética se presenta desde el inicio de nuestra tradición disciplinar como un foco de conflictos y dificultades (Jackson, M., 2011, p. 23); y contribuye así a cierto aislamiento respecto de las ciencias sociales hermanas (Ciuro Caldani, M., 2003, p. 135). Este condicionamiento deriva de una tesis fuerte y ampliamente difundida durante el siglo XX que afirma: la actividad económica es un quehacer para optimizar beneficios al máximo y está libre de influencias morales (Friedman, M. y R., 1980, p. 25).

Suponer que la Economía pueda considerarse inclinada a las prácticas corruptas (Casares Ripol, J., 2011, p. 135) compromete a quienes desde la academia abordamos la disciplina en este veloz y global siglo XXI, a un gran esfuerzo por superar esta crisis; tarea que queda explícitamente planteada como objetivo principal de nuestra colaboración.

Sabemos que ese propósito requiere como primer paso, del diálogo con las otras áreas disciplinares en forma integrada, crítica y abierta (Ciuro Caldani, M., 2011, p. 11); y celebramos la convocatoria de este seminario como una posibilidad para concretarlo.

Partimos de un dato histórico y a la vez paradojal: la Economía como disciplina científica surge en el ámbito de la Ética, que es conocida académicamente durante el siglo XVIII en el mundo anglosajón como Filosofía Moral. Tal el título de la asignatura que por entonces dictaba Adam Smith en las Universidades escocesas de Glasgow y Edimburgo, autor aceptado sin discusiones como el fundador de la Economía en términos científicos; y que escribió varios años antes que su obra maestra Investigación acerca de la naturaleza y de las causas de las riquezas de las naciones (1776) otra aún más significativa: La teoría de los sentimientos morales (1758) donde expone sintéticamente su pensamiento económico posterior (Roll, E., 1973, p. 131).

A partir de este dato de la historia los interrogantes surgen nítidos. Si éste fue el origen de la Economía científica, ¿̇por qué después tendió a aceptar todo tipo de actividades que justificaran un interés para las partes involucradas, suponiendo siempre la legitimidad de los acuerdos basados en la autonomía de la voluntad? Esa supuesta legitimidad chace posible un corrimiento de responsabilidad hacia el sector público quedando marginadas las prácticas corruptas del sector privado? ¿Qué impacto tiene este corrimiento hacia la esfera pública en el 
desarrollo de los países macroeconómicamente más vulnerables?

Buscamos las respuestas posibles, con una metodología crítica (Álvarez Gardiol, A., 2004, P. 65; Habermas, J., 2005, P. 9) integrada en complejidad disciplinar² (Morín, E., 1998, P. 22; Ciuro Caldani, M., 2007, P. 37) y en perspectiva histórica ${ }^{3}$ (Niño Becerra, S., 2015, P. 15; Pérez Luño, A., 2009, P. 21); enfatizando la importancia de la elaboración teórica y su contrastación práctica como instrumentos de reflexión desde y hacia la experiencia (Ayala Rojas, D., 2015). Entendemos a la investigación como un proceso dinámico, cambiante y evolutivo que puede adquirir formas cuantitativas, cualitativas y mixtas (H. Sampieri, R., 2006, P. XXXIX) que deben estar explícitas ${ }^{4}$. En este caso, el artículo es producto de una investigación cualitativa.

Está organizado en torno a tres cuestiones que consideramos centrales en la relación entre Economía y Ética y sostenido por un marco referencial bibliográfico final.

En la primera cuestión, enfocamos la dimensión ideológica, que distingue un criterio basado en la moral y desarrollado por Adam Smith, por una parte; y las posteriores interpretaciones del pensamiento clásico original, por la otra.

En la segunda cuestión, abordamos la dimensión epistemológica, que da cuenta de las dificultades que tiene la doctrina económica para poner en evidencia la necesaria conexión, como parte de su concepto, de la actividad económica con la ética; en especial para la identificación de sus despliegues o externalidades negativas, como la corrupción.

En la tercera cuestión, exponemos la dimensión de la economía política, que está aplicada a la ejecución de políticas públicas macroeconómicas, y por lo tanto, vinculada más estrechamente a la teoría del poder.

Y dejamos así planteada nuestra tesis: La actividad económica es un quehacer ético por su origen (cuidado del bien común) su episteme (toma de decisiones moralmente valiosas) y su ejecución (políticas de desarrollo enfatizadas en la vulnerabilidad).

\footnotetext{
${ }^{1}$ Es crítica porque se sostiene mediante las tareas de reconocer prejuicios cognitivos, identificar y jerarquizar argumentos y valorar las fuentes de información, para lograr razonamientos válidos, consistentes y factibles, especialmente sobre aquellas afirmaciones que la sociedad acepta como verdaderas. Cuestiona las presiones sociales que llevan a la estandarización de los significados. Sostiene que el conocimiento se legitima con la realidad, de allí su denominación, de Kant a Habermas, bajo diversas vertientes. ${ }^{2}$ Es compleja e interdisciplinar porque considera que el estudio de cualquier aspecto de la experiencia humana es, por necesidad, multifacético. No se trata de retomar pensamientos simples para controlar y dominar lo real sino más bien de ejercitarse en pensamientos capaces de integrarse y dialogar con lo real. La consideración de las partes y el todo y viceversa, produce en general, esclarecimientos recíprocos. Este rasgo se ve favorecido cuando la investigación se integra con distintas disciplinas de grado y de posgrado.

${ }^{3}$ Es en perspectiva histórica porque todo suceso es visto como manifestación de un hecho anterior que le dio origen y que es necesario conocer. La investigación debe fortalecer la conciencia histórica acerca de los problemas y no debe confundirse con revisionismos nostálgicos o catastróficos, sino ser competente para detectar los hechos relevantes del pasado.

${ }^{4}$ La fundamentación acerca de la necesidad de explicitar enfoques metodológicos, fue profundizada en nuestra disertación en el Primer Taller de Formación Continua para Becarios de Derecho realizado en la Facultad de Derecho de la UNNE, el 27 de mayo de 2015. Allí sostuvimos que la postura metodológica debe ser ambiciosa, en el sentido de expresar un desafío epistemológico que sabemos de antemano, es difícil de lograr. En esa fuerza motivadora y movilizadora está el progreso de la investigación científica. Claro está, que para que se concrete y produzca los resultados, esperados o no, hay que dominar el marco teórico y las técnicas seleccionadas; y eso es propio de la carrera del investigador que cuanto más formado, mejor conoce sus límites. Resaltamos este aspecto porque la metodología crítica a la que adherimos, básicamente realista en todas sus versiones, es a menudo valorada negativamente como ambiciosa o retórica.
} 


\section{1.- LA DIMENSIÓN IDEOLÓGICA}

Adam Smith sostiene en la obra por la que ha pasado a la posteridad, An Inquiry into the nature and causes of the Wealth of Nations (Smith, A., 1925) que cualquier propuesta que provenga de los empresarios debe analizarse con gran precaución y adoptarse luego de un largo examen, porque ella viene de una clase cuyos intereses no suelen coincidir con los de la comunidad, como lo ha demostrado la experiencia.

Esta afirmación, de por sí polémica viniendo de quien es considerado el padre del capitalismo, nos conduce a indagar más sobre su construcción, relacionada estrechamente con su producción anterior, Teoría de los sentimientos morales (Smith, A., 1941). En ella refleja los orígenes de su formación moral y ética ${ }^{5}$, así como el carácter austero de su ascendencia escocesa y el rigor metodológico obtenido ${ }^{6}$ en las Universidades donde se formó.

El contenido de los dos textos citados es muy amplio, pero en lo que refiere a los objetivos de este trabajo, son cruciales los aspectos éticos presentes en su análisis de la distribución, muy explorada en ambas obras.

Sostiene que la conducta humana es movida naturalmente por seis motivos: el amor a sí mismo, la simpatía, el deseo de ser libre, el sentido de la propiedad, el hábito del trabajo y la tendencia a trocar, permutar y cambiar una cosa por otra. Con estos parámetros de conducta, cada persona es por naturaleza y usando su libertad, el mejor juez de su propio interés, impulsando al mismo tiempo así, el bien común. Esta construcción se corresponde con los tiempos primitivos de la organización social, o pre capitalismo, donde la determinación del valor de cambio de las mercancías se corresponde con la cantidad de trabajo necesario para producirlas. El producto del trabajo pertenece a todos, pues son todos propietarios de mercancías que tienen incorporada determinada cantidad de trabajo de sus dueños (explicado mediante el reconocido ejemplo del costo de cazar castores y venados). En definitiva, en esta etapa de la organización social, las cantidades se igualan en el proceso de cambio.

Con posterioridad y en la convicción del orden natural de las cosas, sostiene que la sociedad evoluciona de ese estado primitivo al de acumulación de stock y apropiación de tierras, conformando así la sociedad capitalista. Lo justifica en aquellas condiciones de conducta que poseen las personas y que les permiten modificar a su favor las condiciones de cambio de algunos con respecto a otros. Reemplaza así la cantidad de trabajo incorporado a una mercancía por el valor del trabajo como medida de valor en sí misma, lo que conlleva a su categorización y a su consideración moral.

Analiza de distinto modo la situación de las personas que han acumulado stock y las que se han apropiado de tierras, distinción que se basa en la diferencia central entre trabajo productivo y trabajo improductivo (que empezó con los fisiócratas y siguió con los mercantilistas, aunque con distinto enfoque) y que se muestra constante en toda búsqueda de las causas de la

\footnotetext{
${ }^{5}$ Con fuerte influencia del empirismo de D. Hume y el naturalismo de J. Locke.

${ }^{6}$ La experiencia académica se advierte en el alto grado de sistematización del pensamiento que alcanzó, en relación con sus predecesores: W. Petty, J. Steuart y R. Cantillon, integrando sus ideas con nuevos significados, que ordenó y reformuló.
} 
riqueza (Smith, A., 1925, p.15).

Define el trabajo productivo como aquel que crea un excedente para su dueño, que aumenta el valor del objeto al que se incorpora. Por lo tanto, solamente admite la acumulación del capital en el sentido expuesto, es decir, ocupando trabajo productivo, trabajo que reemplace y aumente la inversión originaria. Es el único que genera para sus dueños el excedente: la causa de la riqueza, individual y de la Nación (Smith, A., 1925, p. 17).

En el otro extremo ubica a los trabajadores improductivos, que solamente se mantienen de ingresos, entre los que están los acumuladores de la tierra y los trabajadores, aunque después amplía el concepto para incluirlos y comprender todo trabajo que creara un excedente que fuera a recompensar finalmente a los propietarios del stock. Puso atención en los monopolistas, que eran importantes exponentes de la sociedad de transición de su época, resaltando que estaban más ocupados en acumular que en abaratar, perjudicando así el despegue industrial. Con esas consideraciones, el sistema clásico estimulará la industria a expensas de las otras clases, sin abandonar su tesis de armonía necesaria de los intereses sociales.

Si bien refiere a una mano invisible sostenida por la creencia en el orden natural de las cosas, que hacía que todos contribuyeran al bien común, no soslaya su opinión acerca de la situación de los llamados trabajadores improductivos. Preservando las instituciones, descalificó la prodigalidad de los príncipes y de los ministros que le sirven, tanto judiciales como militares y de algunas profesiones y oficios (Smith, A., 1925, p. 356). También puso en duda la calidad intelectual y el carácter de los terratenientes al decir que obtienen sus ingresos sin trabajar gustando de cosechar donde no han sembrado (Smith, A., 1925, p. 50); y, por lo tanto, a menudo ignoran su propio interés o son incapaces de comprender algunas medidas que podrían afectarles. Sin embargo, sus intereses deben ser tenidos en cuenta porque sus rentas suben con el aumento general de la riqueza y así contribuyen a la armonía general. Los intereses de los obreros también cuentan, aun cuando éstos no son capaces, la mayoría de las veces, de comprender cuál es la importancia de su papel en la producción y por qué están allí. Finalmente, al ocuparse de los intereses de los capitalistas, es decir, de los que viven de utilidades, dice que son más capaces que cualquier otra clase para apreciar sus propios intereses y por lo tanto, es sospechosa su actitud, tanto hacia la política pública como hacia el resto de las clases. Y aquí surge su recomendación de analizar sus propuestas con precaución y al mismo tiempo, de fortalecer su conducta; párrafo con el que iniciamos este punto.

Esta convicción lo lleva a concluir que la burguesía, encarnada en propietarios de unidades productivas, debía ser libre para actuar, pero sin abandonar la necesaria visión colectiva para evitar que el individualismo arrasase con los intereses de la comunidad.

Para lograrlo, debía intensificarse la educación de la nación, en sintonía con las pro-puestas empiristas de su amigo, el pedagogo y político David Hume.

El pensamiento de Smith fue objeto de numerosas interpretaciones, entre las que se destaca la de David Ricardo en Principles of Political Economy and Taxation (Ricardo, D., 1926) quien se ocupó de difundirla lo más posible y de sistematizar el pensamiento clásico. Aunque 
carecía de todas las ventajas de la exquisita educación académica de su predecesor, expuso sus ideas con riguroso método deductivo.

Ricardo trata de demostrar que el trabajo crea valor en todo momento, en la producción capitalista como en la primitiva, tanto mediante el trabajo presente como el pasado (incorporado en este último caso en los instrumentos herramientas, edificios) por lo que se diferencia de Smith al jerarquizar al capital como verdadero creador del valor, dando fundamento al sistema capitalista como no se había hecho antes, y por lo tanto, a los derechos de los dueños del capital.

Pinta un cuadro pesimista y de conflicto de las fuerzas productivas. Destruye implícitamente la armonía de los intereses sociales de Smith y su corrección moral. El interés del terrateniente se opone al del obrero y el industrial y también entra en pugna con el interés general de la sociedad.

Este criterio sobre el valor afecta la teoría del orden natural. Los intereses de los factores no se corrigen automáticamente en igualdad de condiciones, sino que priman los intereses del capital porque éste es el factor primordial. Sostiene que el trabajo es una mercancía cuyo valor debe determinarse del mismo modo que cualquier otra; y ese valor será el necesario para permitir a los trabajadores subsistir y perpetuar la especie, sin aumento ni disminución (Ricardo, D., 1926, p. 175).

Presenta una teoría del trabajo dominada por el capital, aunque sin entrar en la explotación; categorización que después desarrolló Carlos Marx como lucha de clases. Para Ricardo, el conflicto moral estaba planteado en esa relación de factores.

Explora también sobre el valor del dinero. Había presenciado la depreciación moneta-ria y la cesación de pagos de la época (fines del siglo XVIII), que lo llevaron a elaborar una teoría cuantitativa de la moneda, la importancia de la banca y de los pagos internacionales, otorgando relevancia a uno de los aspectos hoy más cuestionados de la ética económica: el capitalismo financiero. Pone de manifiesto que la inflación y la depreciación ocasionaban una salida de oro y propuso que el Banco de Inglaterra redujese la cantidad de billetes en circulación hasta que el precio del oro hubiera bajado. Su propuesta fue aceptada y la legislación bancaria posterior refleja la influencia ricardiana en todo el mundo, lo que significa admitir que el alza o la baja de los precios relativos de la economía se debe a un exceso o un defecto de la cantidad de moneda en circulación y es causa principal de la inflación.

El aspecto financiero de la actividad económica adquiere una profundización mayor con el desarrollo del liberalismo libertario (Mises, L., 1949; Hayek, F., 1944)) y el monetarismo de la Escuela de Chicago (Friedman, M., 1980); de amplias influencias en los gobiernos de América Latina y el Caribe durante el siglo XX. Para ambos, los gobiernos pueden y deben decidir como éticamente correcta la liquidez moderada del sistema, como único modo de intervención en la vida económica dejando al mercado la libre elección de las transacciones, tanto internas como externas. La economía se considera así como la disciplina que protege los acuerdos voluntarios entre adultos, los que se presentan siempre morales y legítimos bajo el amparo de la autonomía de la voluntad. 
El desarrollo del aspecto financiero de la actividad económica, conlleva dos posiciones extremas en torno al papel del Estado en el siglo XX tendientes a resolver si éste puede o no corregir las distorsiones del mercado, lo que no es otra cosa que discutir el dilema ético del capitalismo mediante las teorías macro económicas y del Estado de Bienestar. En su máxima expresión, el Estado de Bienestar justifica la intervención estatal como una garantía de distribución justa, porque el Estado es un referente ético, un garante del bien común ${ }^{7}$ (Keynes, J., 2001, p. 23). Esta idea condujo a Keynes a revisar la agenda del Estado y a modificar en consecuencia, la doctrina del laissez - faire, en contraste con la posición de la Escuela Clásica.

En la actualidad, la doctrina muestra un regreso paulatino a la investigación micro-económica (Bermejo Barrera, J., 2015, p. 229) que se nutre de la dimensión ética para explicar las decisiones individuales (Mattei, U., 2013, p.13) y utiliza la autoevaluación como primer modo de reflexión de la conducta tanto individual como social (Lousteau, 2011, p. 15). Este regreso a la microeconomía (White, L., 2014, p. 13) está fundado tanto en las grandes crisis financieras como de la deuda de los Estados contemporáneos (Manera, C., 2015, p. 116) las que en definitiva son vistas como crisis de las personas.

Angus Deaton y la Escuela de Princeton ${ }^{8}$ (Deaton, A., 1991) subrayan el papel del Estado en el logro de la felicidad de los ciudadanos y la diferente visión de austeridad entre países según su nivel de desarrollo. Sostienen que es preciso indagar de qué manera consumen los individuos, qué decisiones personales toman respecto a sus ingresos, en qué grado de desarrollo lo hacen, y por qué la sociedad capitalista pone énfasis en el crédito como motor de la sociedad y su contracara, la deuda; desplazando al intercambio tradicional y construyendo una subjetividad - y una moral correspondiente -: la del hombre endeudado9 (Lazzaratto, M., 2013).

Las líneas de investigación más actuales trabajan desde esta perspectiva y expresan que la pobreza es básicamente la consecuencia de un desarrollo desigual, de Estados ineficaces y de mediciones sin control técnico real.

En ese estado del arte ${ }^{10}$ están los aportes de la disciplina.

\footnotetext{
${ }^{7}$ En el contexto histórico y político en que se desarrolla el pensamiento de Keynes y su Teoría General, los problemas a resolver eran: la reconstrucción de las economías devastadas por la Segunda Guerra Mundial, la emergencia de antiguas colonias como países sub desarrollados y la lucha contra la inflación. Keynes sostiene que el papel del Estado debía ser defender al país de las agresiones externas y asegurar el cumplimiento de los derechos adquiridos, frente a la incapacidad de los mercados para generar por sí mismos el pleno empleo y con ello, la estabilidad económica y la prosperidad. De allí la necesidad de una actividad pública supletoria o Estado Benefactor.

${ }^{8}$ El discurso sobre el hombre endeudado puede percibirse sobre todo a través de los medios de comunicación y suele presentarse como una contradicción. Por un lado, que somos una nación endeudada y tenemos que asumir las consecuencias; y por el otro, que de ninguna manera somos culpables como individuos y por lo tanto tenemos derecho a acceder a todos los bienes que nos muestran para comprar.

${ }^{9}$ El discurso sobre el hombre endeudado puede percibirse sobre todo a través de los medios de comunicación y suele presentarse como una contradicción. Por un lado, que somos una nación endeudada y tenemos que asumir las consecuencias; y por el otro, que de ninguna manera somos culpables como individuos y por lo tanto tenemos derecho a acceder a todos los bienes que nos muestran para comprar.

${ }^{10}$ Conocido también como revisión de la literatura, el Estado del Arte constituye una tarea inicial de todo proceso de investigación para identificar qué se hizo antes, qué se hace ahora y para qué. Explica lo acumulado hasta el presente y su lógica investigativa. Le da una dirección inicial al proceso de búsqueda.
} 


\section{2.- LA DIMENSIÓN EPISTEMOLÓGICA}

Arvind Jain en The Political Economy of Corruption (Jain, A., 2001) afirma la necesidad de incorporar la ética al concepto mismo de actividad económica como un asunto epistemológico, porque es la definición del concepto la que determina qué se modela y qué se mide. En ese sentido, lo primero que se presenta para el análisis es el concepto de corrupción como despliegue negativo de la relación entre la Ética y la Economía.

Existe un vacío conceptual que conduce a que algunos economistas adopten una definición estrecha y por tanto inadecuada de la corrupción, como referencia a la ausencia de ética en la actividad económica, que afecta también al carácter y al contexto del discurso contra la corrupción (Bukovansky, M., 2006, p. 181) que quedan de este modo limitados a ciertos temas y esferas, ajenos a la disciplina económica.

El primer condicionante es la limitación del concepto al sector público, aunque ni la etimología de la palabra ni su definición autorizada restringen la aplicación de su significado a ese sector ${ }^{11}$. Por lo tanto, la corrupción también se puede producir en la esfera privada y así lo señalan algunas organizaciones internacionales como la Oficina de Naciones Unidas sobre Drogas y Crimen y programas globales como Transparencia Internacional. ${ }^{12}$

Pero entre los economistas la idea de la mayoría es diferente. En general, coinciden en afirmar que la corrupción se refiere a actos en los que el poder del cargo público se usa para beneficio personal de una manera que contraviene las reglas de juego acordadas en el mercado (Jain, A., 2001, p. 73-120) y en el mismo sentido la Escuela de Cambridge con Toke Aidt (Aidt, T., 2003, p. 632-652). Esta tendencia se manifiesta en otras producciones científicas y académicas que, si bien utilizan la expresión corrupción sin adjetivos, en su desarrollo solamente refieren a la corrupción del sector público soslayando la del sector privado ${ }^{13}$. En algunos casos, economistas que trabajan el concepto en relación con la democracia, sostienen con énfasis que se circunscribe a la corrupción de los gobiernos y la definen como pagos que se hacen ilegalmente a los agentes públicos con el fin de obtener beneficios o evitar costos (Rose Ackerman, S.,1999, p. 9).

Sí existe una literatura académica que va en aumento, sobre la ética de la empresa a la que se identifica como responsabilidad social empresaria, aunque está dirigida a la gobernanza corporativa ${ }^{14}$ y no a la actividad económica en general, quizá por eso el uso de otras expresiones para definirla excluyendo a la ética, por lo que todavía es objetable.

\footnotetext{
${ }^{11}$ La palabra corrupción proviene del adjetivo latino corruptus que significa estropeado, descompuesto o destruido. Para el Concise Oxford English Dictionary el significado social de corromper es sobornar; y de corrupción, deterioro moral.

${ }^{12}$ Organización no gubernamental (1993) con sede en Berlín, que se ocupa de publicar anualmente un índice de percepción de corrupción a nivel mundial. Define la corrupción como el abuso de poder para beneficios privados y depende de la integridad de las personas en una posición de autoridad.

${ }^{13}$ Cabe aclarar que Adam Smith ya reconoció el problema de la corrupción en la esfera privada, a la que denominó malversación moral. El modo en que fue evolucionando el pensamiento económico dejó en un segundo plano las ideas originales de este autor por las interpretaciones de los autores clásicos posterio-res como se menciona en el punto 2 de este texto.

${ }^{14}$ La expresión se utiliza para explicar el procedimiento para tomar decisiones en asuntos complejos que comprometen distintos niveles de la organización empresarial, como el trato equitativo de los accionistas, el manejo de los conflictos, la estructura del capital, los incentivos, el control, la revelación de información, la influencia de inversionistas institucionales y todos los aspectos que pueden afectar la distribución de las rentas.
} 
Otro condicionante epistémico es el de considerar que la corrupción puede justificarse por causas nobles, es decir, cuando el acto corrupto no se realiza estrictamente para beneficio privado (más allá de la idea utilitarista que todas las acciones se realizan para incrementar una satisfacción individual). Nos referimos, aunque parezca extraño, a casos donde las personas actúan corruptamente, pero con fines morales o motivos superiores, fabricando u ocultando pruebas o mintiendo piadosamente para proteger a alguien.

Alguna vez se ha dicho que, ante una ausencia de vinculación expresa y explícita entre la moral y la actividad económica, podría inferirse que el acto inmoral puede ser compensado por los resultados morales de la causa noble. Nada más inconveniente para el desarrollo actual de la Economía. La corrupción no tiene justificación moral y produce externalidades negativas ${ }^{15}$ (Coase, R., 1988, p. 213).

No es aceptable reducir la moralidad a términos de utilidad sino más bien de costos de las decisiones personales, costos que se basan en convicciones - o preferencias - morales que implican la aceptación de reglas sociales, entre las que están también las jurídicas, porque el mercado no es una zona exenta de moralidad (Schultz, W., 2001).

\section{3.- LA DIMENSIÓN DE LA ECONOMÍA POLÍTICA}

Finalmente nos preguntamos cómo puede afectar la comprensión adecuada de la relación entre la Ética y la Economía, a la ejecución de las políticas públicas macroeconómicas; en particular, a la construcción del desarrollo de las sociedades más vulnerables (Ferrer, A., 2015, p. 35) teniendo en cuenta que el desarrollo desigual es una violación de la dignidad y una negación de la posibilidad de evolución de la capacidad humana (Therborn, G., 2015, p. 11).

$\mathrm{Al}$ respecto, la Economía presenta desde hace más de cincuenta años, una categorización de las causas de vulnerabilidad en los países, que por entonces se conocía generalizadamente como subdesarrollados; categorización que constituye una de las aproximaciones, a nuestro juicio, más relevantes de la integración entre Ética y Economía; y de ambas con el Derecho $^{16}$ (Ghersi, C., 2014, p. 1-4).

Se trata de la conceptualización que elaboró en 1960 el economista francés Raymond Barré y que hasta la fecha parece presidir de una u otra manera los debates que, acerca del desarrollo, se realizan en los foros de todo el mundo.

\footnotetext{
${ }^{15}$ Las externalidades negativas son decisiones que toman las personas en sus relaciones de producción y consumo y que afectan a terceros, no partícipes de esas transacciones. Llevan a los gobiernos a intervenir en la economía. Como no se expresan, no se trasladan a los precios. Por lo tanto, las partes intervinientes se benefician con costos menores y los verdaderos costos se trasladan a la sociedad en su conjunto, que responde con desconfianza y anomia porque no cumplir la norma es menos costoso que cumplirla. ${ }^{16}$ El ser digno - ser humano - y el trato digno conforman un principio general del derecho que se expande por todo el ordenamiento jurídico con jerarquía constitucional.
} 
Dice Barré que una economía subdesarrollada puede reconocerse si cumple con los siguientes requisitos: una estructura primaria y dual, donde su funcionamiento se caracteriza por la inestabilidad y la dependencia política, económica y/o jurídica; que, por su combinación, difícilmente permite a sus habitantes romper el círculo vicioso de la pobreza (Barré, R., 1962, p. 16).

La estructura primaria se sostiene con los recursos naturales del país, esto es, en dependencia directa de la naturaleza. La producción primaria (agrícola, ganadera, forestal, minera, pesquera, etc.) es la base fundamental y a veces única de la economía nacional, no solamente para el mercado interno sino también para sus exportaciones. Desde luego que, en cierto sentido, todas las comunidades humanas sin importar cuan industrializadas estén, viven de la tierra. Una interesante diferencia entre una sociedad industrial y una agrícola - en términos de intercambio - es la cantidad de población no agrícola a la que los agricultores pueden dar sustento. Un agricultor de país desarrollado con terreno y tecnología disponibles podría en óptimas condiciones alimentar a más personas que no se dediquen a la agricultura; mientras que un agricultor de país subdesarrollado falto de terreno y tecnología puede verse muy presionado, después de pagar al dueño de la tierra, para dar sustento siquiera a su propia familia, la mayoría de las veces dependiente de él y numerosa. Además, algunas políticas públicas favorecen el monocultivo, lo que hace más vulnerable aún las estructuras primarias porque dependen de la variación del precio de un solo cultivo en el mercado mundial, como en los últimos años ha ocurrido con la soja en América del Sur (Rodríguez, C., 2015, p. 291).

La estructura primaria también tipifica las fuerzas productivas, que se agrupan entre los que adquieren la propiedad de la tierra y los que no. Los primeros, con posibilidades crecientes de acumulación. Los segundos, destinados por generaciones al trabajo rural, generalmente en familia y para un solo patrón, que los forma bajo esas condiciones y con valores que se denominan tradicionales. La resolución de los problemas económicos por la tradición produce sociedades estáticas, hereditarias y poco proclives a los cambios, lo que hace que el tenor de su vida permanezca constante (Heilbroner, R. y Milberg, W., 1999, p. 7). Los valores a considerar son la seguridad y la certeza; y en las sociedades menos desarrolladas y de rasgos feudales, el agradecimiento y la fidelidad.

Con frecuencia, sobre la base de la sociedad tradicional, se construyen modos autoritarios de control económico, de autoridad impuesta o mando, donde el poder del Estado participa activamente. Es una solución que básicamente, no aspira solo a reproducir sin cambios, sino a organizar un sistema viable mediante órdenes superiores e ideas matrices, que por sus implicancias y profundizaciones será objeto de otros artículos.

El autor pone énfasis en el dilema ético de la sociedad dual a la que denomina así porque conviven en ella dos sociedades. Una feudal, precaria y sin los servicios públicos básicos, y la otra opulenta, con todos los servicios, al estilo de las grandes ciudades del mundo. Pero el dilema difícil no reside en su sola existencia sino en el reconocimiento que una hace de la otra. Los pobres hablan de los ricos y los ricos se refieren a los pobres como si fueran partes 
necesarias e inmodificables de una misma sociedad. La categorización de unos por otros en el lenguaje corriente, propone sin pudor, su continuidad (Ayala Rojas, D., 2011, p. 105) y hace difícil superar la pobreza estructural que se alimenta de sus componentes.

La estructura primaria y dual descripta favorece la inestabilidad y la fragilidad de todo el sistema. La inestabilidad política se caracteriza por golpes de Estado y gobiernos de facto durante el siglo XX en América del Sur y que durante el presente siglo adquieren otras formas, como las crisis institucionales o democráticas como la de 2001 - 2002 en la Argentina, donde el descontento social se sintetizó en la frase "que se vayan todos". La inestabilidad económica se manifiesta macroeconómicamente por la inflación, el desempleo y la exclusión, de manera constante con diferentes grados de intensidad. La inestabilidad jurídica se incorpora en el siglo XXI cuestionando la idoneidad del Poder Judicial y su producto social, la Justicia, ante los niveles de corrupción alcanzados por los otros poderes del Estado, sobre los que el Poder Judicial debería ejercer el control de constitucionalidad.

La dificultad en romper el círculo vicioso de la pobreza, metáfora perdurable en la definición de subdesarrollo que analizamos, es el resultado multifacético del ahogo del proceso productivo, por una parte, que condena a la población a consumir sus ingresos, no le permite ahorrar y mucho menos invertir, afectando tanto su calidad de vida como la sostenibilidad social; y por la otra, de una desatención de los componentes éticos del intercambio por el conjunto del sistema, soslayando su función de creador de valor para toda la sociedad y en su expresión mayor, para toda la humanidad.

\section{CONCLUSIÓN}

Creemos que la Economía puede y debe participar activamente de debates conjuntos e interdisciplinares sobre estas cuestiones no solo porque le competen sino porque, además, le afectan en el modo de ser percibida socialmente. Quizá sea momento de centrar el foco de análisis en el intercambio, con una participación que supere la clásica contraposición producción - distribución, que dominó todo el siglo XX y que parece no ser suficiente para rebatir la tesis que la actividad económica es un quehacer para optimizar beneficios y, por tanto, libre de influencias morales. Poner el foco en el intercambio es permitirnos construir relaciones en términos de igualdad, es decir, de humanidad, donde la dimensión económica no se agota en la obtención máxima de beneficios, sino que procura lograr el mayor disfrute de los bienes comunes ( Mattei, H.,2011, p. 16.) mediante decisiones que implican en su dimensión jurídica, ejercicio de libertades, restricciones y límites (Casares Ripoll, J., 2011, p. 77.) en interacción compleja en las esferas tanto privadas como públicas; y en su dimensión ética, con personas - privadas y públicas - que procuren resultados siempre valiosos en términos de conjunto social y no solamente de factores productivos. 
Por lo expuesto, sostenemos que la actividad económica es un quehacer ético por su origen (cuidado del bien común) su episteme (toma de decisiones moralmente valiosas) y su ejecución (políticas de desarrollo enfatizadas en la vulnerabilidad).

Nos proponemos desafiar las fronteras de la desconfianza y los prejuicios mutuos (Baumann, Z., 2015, p. 133) integrándonos al debate para conocer qué espera la sociedad de nuestra disciplina y de nosotros, los académicos; quienes, con distinto alcance y la misma responsabilidad, la representamos.

\section{REFERENCIAS BIBLIOGRÁFICAS}

Aidt, T. (2003). Economic analysis of corruption en Economic Journal. $\mathrm{N}^{\mathrm{o}}$ 113-8. UK. London Press.

Álvarez Gardiol, A. (2004). Lecciones de Epistemología. Santa Fe: UNL.

Ayala Rojas, D. (2011). El derecho ante los desafíos de la globalización en Revista de la Facultad de Ciencias Económicas, $\mathrm{N}^{\circ}$ 7, 105 - 122. Universidad Nacional del Nordeste. Disponible en http://eco.unne.edu.ar/revista/publicaciones/revista_7_AyP_digital.pdf

Barré, R. (1962). El desarrollo económico. Análisis y política. México: Fondo de Cultura Económica.

Bauman, Z. (2015). Ceguera moral. Buenos Aires: Paidós.

Bermejo Barrera, J. (2015). La tentación del rey Midas. Madrid: Siglo XXI.

Bukovansky, M. (2006). The hollowness of anti corruption en Review of international political economy. $\mathrm{N}^{\mathrm{o}}$ 13.2. UK: London Press.

Casares Ripol, J. (2011), Ética, Economía y Política. Madrid: Esic.

Ciuro Caldani, M. (2011). Estrategia Jurídica. Rosario: UNR Editora.

Ciuro Caldani, M. (2007). Dos Filosofías del derecho argentinas anticipatorias. Rosario: Fundación para las investigaciones jurídicas. 
Ciuro Caldani, M. (2003) Lecciones de Filosofía de Derecho Privado. Rosario: Fundación para las investigaciones jurídicas.

Coase, R. (1988). The firm, the market and the law. Chicago: University of Chicago Press.

Deaton, A. (1991). Understanding consumption. Oxford: Clarendon Press.

Ferrer, A. (2015). La economía argentina en el siglo XXI. Buenos Aires: Capital intelec-tual.

Friedman, N y R. (1980). Libertad de elegir. (Trad. C. Rocha Pujol). Madrid: Grijalbo.

Ghersi, C. (2014). La dignidad como principio general del derecho. En La Ley. Año LXXVIII No 148. (1 - 4). Buenos Aires: La Ley.

Habermas, J. (2005). Facticidad y validez. Madrid: Trotta.

Hayek, F. (1944). Camino de servidumbre. UK: Rutledge Press.

Hernández Sampieri, R. (2006). Metodología de la investigación. México D.F.: Mc Graw Hill Interamericana.

Heilbronner, R., y Milberg, W. (1999). La evolución de la sociedad económica. México D.F.: Prentice Hall.

Jain, A. (2001). Corruption a review en Journal of economic surveys. $\mathrm{N}^{\circ} 15.1$. Montreal: John Molson School of Business Press.

Jackson, T. (2011). Prosperidad sin crecimiento. Barcelona: Encuentro.

Keynes, J. (2001). Teoría general de la ocupación, el interés y el dinero. Buenos Aires: Fondo de Cultura Económica.

Lazzaratto, M. (2013). La fábrica del hombre endeudado. Madrid: Amorrortu.

Lousteau, M. (2011). Economía 3D. Buenos Aires: Sudamericana.

Manera, C. (2015). La extensión de la desigualdad. Madrid: Catarata. 
Mattei, U. (2013). Bienes comunes. Madrid: Trotta.

Mises, L. (1949). Human action. New Haven: Yale University Press.

Niño Becerra, S. (2015). La economía, una historia muy personal. Barcelona: Los Libros del Lince.

Pérez Luño, A. (2009). La Filosofía del Derecho en perspectiva histórica. Sevilla: Universidad de Sevilla.

Piketty, T. (2014). El capital en el siglo XXI. Madrid: Fondo de Cultura Económica.

Rodríguez, C. (2015). Lecciones de Economía Política. Corrientes: Moglia.

Ricardo, D. (1926) Principles of political economy and taxation. UK: Everyman.

Roll, E. (1973). Historia de las doctrinas económicas. México: Fondo de Cultura Económica.

Rose Ackerman, S. (1999). Corruption and government. Causes, consequences and reform. Cambridge: Cambridge University Press.

Schultz, W. (2001). The moral conditions of economic efficiency. Cambridge: Cambridge University Press.

Smith, A. (1941). Teoría de los sentimientos morales. (Trad. E. O Gorman). México: El Colegio.

Smith, A. (1925). An inquiriy into the nature and causes of the wealth of Nations. UK: Scott.

Stiglitz, J., Sen, A. y Fitoussi, J. (2013). Medir nuestras vidas. Barcelona: RBA Libros.

Therborn, G. (2013). La desigualdad mata. Madrid: Alianza.

White, L. (2014). El choque de ideas económicas. Barcelona: Bosch. 


\section{CURRICULUM VITAE}

\section{Dora Esther Ayala Rojas}

PhD en Principios Fundamentales y Derechos Humanos, con Certificación Postdoctoral de la Universidad de Ciencias Empresariales y Sociales de la República Argentina, UCES. Doctora en Derecho por la Universidad Nacional de Rosario. Especialista en Derecho Tributario por la Universidad Nacional del Litoral y la Universidad de Salamanca, España. Especialista en Docencia Universitaria por la Universidad Nacional del Nordeste. Abogada. Profesora Titular con Dedicación Exclusiva. Investigadora categorizada. Directora de PI acreditados. Con jueza de la Cámara Federal de Apelaciones de Corrientes, 2013-2015.

estudiojuridicocontablenotarial@hotmail.com 